Jurnal Indonesia Sosial Teknologi: p-ISSN: 2723 - 6609

e-ISSN : 2745-5254

Vol. 2, No. 9 September 2021

\title{
PEMANFAATAN BUAH MARKISA MENJADI PRODUK OLAHAN BERNILAI EKONOMIS DI KELURAHAN SUKORAME GRESIK
}

\author{
Budi Prabowo', Rafli Septian $D^{2}$, Amalus Solecha ${ }^{3}$, Mustati'Uliyah ${ }^{4}$, M. Zidan \\ Izani $^{5}$, Lilis Nur Afiah ${ }^{6}$, Danang Suryo M. ${ }^{7}$, Maulana Taufik H. ${ }^{8}$, Rahma Amelia ${ }^{9}$ \\ Universitas Pembangunan Nasional "Veteran" Jawa Timur 1-9 \\ Email: bprabowo621@gmail.com¹, 18024010030@student.upnjatim.ac.id², \\ 18012010003@student.upnjatim.ac.id ${ }^{3}$, 18042010036@student.upnjatim.ac.id ${ }^{4}$, \\ 18011010086@student.upnjatim.ac.id ${ }^{5}$, 18042010094@student.upnjatim.ac.id ${ }^{6}$, \\ 18044010066@student.upnjatim.ac.id ${ }^{7}, 18082010053 @$ student.upnjatim.ac.id $^{8}$, \\ 18042010082@student.upnjatim.ac.id ${ }^{9}$
}

\begin{abstract}
Abstrak
Markisa merupakan tanaman yang memiliki banyak manfaat, baik dari segi estetika maupun fungsional. Markisa dapat digunakan sebagai tanaman pergola, serta dapat dimanfaatkan baik dari buah maupun daunnya. Oleh karena itu tanaman markisa menjadi salah satu tanaman potensial yang layak dibudidayakan, seperti yang dilakukan di Kelurahan Sukorame, Kabupaten Gresik. Untuk memajukan hasil olahan markisa tersebut, kami membuat beberapa inovasi olahan baru yaitu menjadi olahan sirup markisa dan juga selai markisa, solusi manajemen diberikan kepada pembudidaya mulai dari proses pembuatan hingga pemasaran produk olahan markisa. Pemanfaatan buah markisa menjadi produk olahan dapat menambah nilai ekonomis dari buah markisa dan menjadi peluang usaha yang dapat menghasilkan keuntungan serta meningkatkan perekonomian warga kelurahan Sukorame.
\end{abstract}

Kata kunci: markisa; olahan markisa; peningkatan nilai ekonomis.

\section{Abstract}

Passion fruit is a plant that has many benefits, both in terms of aesthetics and functional. Passion fruit can be used as a pergola plant, and can be used both from its fruit and leaves. Therefore, passion fruit is one of the potential plants that deserves to be cultivated, as was done in Sukorame Village, Gresik Regency. To advance these passion fruit products, we created several new processed innovations, namely passion fruit syrup and passion fruit jam, management solutions are provided to cultivators from the manufacturing process to marketing the passion fruit processed products. Utilization of passion fruit into processed products can add to the economic value of passion fruit and become a business opportunity that can generate profits and improve the economy of the residents of the Sukorame village.

Keywords: passion fruit; processed passion fruit; increase in economic value. 


\section{Pendahuluan}

Di Indonesia banyak ditemukan beraneka ragam buah-buahan. Terdapat 22 jenis buah yang dapat dipanen setiap tahunnya. Menurut Badan Pusat Statistik Indonesia, produksi buah pada tahun 2020 sebagian besar meningkat dibandingkan tahun sebelumnya. Salah satu jenis buah yang produksinya meningkat adalah buah markisa. Produksi buah markisa membesar sekitar 53319,00 ton. Markisa (Passiflora sp.) termasuk ke dalam famili Passifloraceae yang berasal dari Amerika Selatan. Jenis markisa yang dibudidayakan di Indonesia meliputi markisa asam dengan kulit buah berwarna ungu disebut siuh atau purple passion fruit (P. edulis f. edulis Sims), markisa asam dengan kulit buah berwarna kuning disebut juga rola atau yellow passion fruit ( $\mathrm{P}$. edulis Sims f. flavicarpa Deg.), markisa konyal atau markisa manis (P. ligularis Juss), dan erbis atau giant granadilla (P. quadrangularis L.) (Karsinah, Silalahi, \& Manshur, 2007).

Lantaran markisa merupakan tanaman merambat, maka petani perlu membuat para-para ataupun media rambat lain dengan tinggi tiang sekitar dua meter. Dengan demikian, markisa dapat difungsikan sebagai tanaman pergola. Selain dapat dimanfaatkan untuk tanaman pergola, di dalam buah markisa terkandung berbagai manfaat untuk kesehatan tubuh. Markisa asam bermanfaat terhadap penghambatan sel kanker serta penurunan kolesterol karena kandungan seratnya yang cukup tinggi, yaitu mengandung serat diet sekitar 10,40 g atau 27\% (Marpaung \& Karo, 2016). Buah markisa juga merupakan sumber vitamin C yang baik, dimana Vitamin C dapat berfungsi meningkatkan kekebalan tubuh dan sebagai antioksidan alami (Susanti \& Putri, 2014). Dengan berbagai manfaat yang terkandung di dalamnya, buah markisa sangat baik untuk dikonsumsi dan dibudidayakan.

Pertanian di perkotaan yang berlokasi di Kelurahan Sukorame Kecamatan Gresik terdapat satu kampung yang dinamai Kampung Markisa yang menjadi salah satu lokasi percontohan dimana masyarakat dilingkungan warga tersebut benar- benar memanfaatkan lahan sempit seperti jalan perkampungan yang disulap menjadi pertanian markisa. Dalam pemanfaatan buah markisa seutuhnya masyarakat Kampung Markisa melakukan berbagai usaha pengolahan dan pemanfaatan buah markisa seutuhnya. Salah satunya menjadi minuman markisa, yang dapat menjadikan markisa sebagai olahan yang bernilai ekonomis kendala terbesarnya adalah masyarakat Kampung Markisa tidak mempunyai olahan produk lainya selain minuman markisa, yang diharapkan menambah variasi olahan produk agar pembeli lebih tertarik dan memiliki referensi lainnya selain minuman markisa yang telah ada. Untuk mengatasi hal ini, tim KKN 82 UPN "Veteran" Jawa Timur membantu Kelurahan Sukorame dalam menangani tentang penambahan variasi olahan dari buah markisa, diantaranya adalah pembuatan sirup dari buah markisa, serbuk dari buah markisa dan selai dari buah markisa. Selain itu tim KKN 82 UPN "Veteran" Jawa Timur 2021 juga membantu soal desain kemasan produk yang baik dan menarik agar dapat menambah nilai jual produk yang tersedia.

Pengembangan komoditas buah menjadi salah satu sumber pertumbuhan ekonomi di Indonesia. Selain sebagai perkembangan agribisnis baik produsen hingga 
Budi Prabowo ${ }^{1}$, Rafli Septian D ${ }^{2}$, Amalus Solecha ${ }^{3}$, Mustati'Uliyah ${ }^{4}$, M. Zidan Izani ${ }^{5}$, Lilis Nur Afiah ${ }^{6}$, Danang Suryo M. ${ }^{7}$, Maulana Taufik H. ${ }^{8}$, Rahma Amelia ${ }^{9}$

konsumen, buah digunakan untuk memperbaiki keseimbangan gizi (Sugiarti, 2014). Ada beberapa faktor potensi pengembangan tanaman buah-buahan di Indonesia diantaranya.

\section{Metode Penelitian}

Metode Historis yaitu, metode penelitian yang meliputi pengumpulan data dan penafsiran gejala peristiwa yang timbul dimasa lalu yang menggambarkan secara kritis seluruh kebenaran kejadian atau fakta untuk membantu mengetahui apa yang harus dikerjakan dimasa datang.

Kampung ini diberi julukan Kampung Markisa. Sebab di kelurahan ini dikenal dengan olahan buah markisa. Sejarahnya sebenarnya tidak sengaja. Nama kampung ini Sukorame, Kecamatan Gresik, Jawa Timur. Dulu di tahun 2017 warga RT 1 RW 1 Sukorame meminta pada anak usaha Pertamina, yaitu PT. Pertamina Lubricants melalui Production Unit Gresik (PUG) untuk memberikan pada mereka tanaman peneduh. Fungsinya untuk penghijauan. Kebetulan kemudian mereka diberikan bibit markisa yang ditanam di pekarangan penduduk. Mereka juga mendapat bantuan anjang-anjang untuk dipasang di sepanjang jalan kampung. Tujuannya sebagai media bagi tumbuhnya markisa. Sebab markisa adalah jenis tumbuhan merambat dan proses selanjutnya, karena markisa yang ditanam tumbuh subur dan berbuah banyak, warga mulai mengolahnya menjadi minuman. Dari sanalah kemudian sebutan Kampung Markisa mereka dapatkan. Bantuan dari Pertamina tidak berhenti di sana. Melalui anak usahanya, Pertamina juga membangun perpustakaan dan rumah produksi yang resmi dibuka pada 10 November 2020. Bangunan itu bukan hanya sebagai tempat pendidikan, namun juga difungsikan sebagai sarana pengembangan ekonomi, sosial dan lingkungan bagi masyarakat (Qadaruddin, Nurkidam, \& Firman, 2016).

Metode Ekperimen yaitu, metode yang digunakan sebagai uji coba atau percobaan yang dilakukan pada objek tertentu untuk mencapai hasil yang diinginkan (Afifah, 2015). Hal ini dilakukan untuk melakukan inovasi baru terhadap buah markisa supaya bisa diolah menjadi olahan lain selain minuman kemasan yang saat ini diproduksi oleh kelurahan Sukorame atau bisa dikatakan bagaimana cara mengolah buah markisa menjadi olahan yang bermacam macam.

(Wirantasa, 2017) menyatakan bahwa penelitian survei adalah penelitian yang dilakukan pada populasi besar maupun kecil, tetapi data yang dipelajari adalah data dari sampel yang diambil dari populasi tersebut, untuk menemukan kejadian- kejadian relatif, distribusi, dan hubungan-hubungan antar variabel sosiologis maupun psikologis. Teknik pengumpulan data yang digunakan pada kegiatan yang kami lakukan adalah wawancara.

\section{Hasil dan Pembahasan}

Kelurahan Sukorame Kabupaten Gresik merupakan salah satu Kelurahan yang menjadikan markisa sebagai ikon kelurahan, serta mengolahnya menjadi produk siap 
jual sehingga buah markisa menjadi lebih bernilai ekonomis (Ihsan, Firza, Edward, Firmansyah, \& Abdullah, 2021).

Pemanfaatan buah markisa yang dilakukan oleh Kelurahan Sukorame adalah dengan menghasilkan produk olahan dari buah markisa, yaitu minuman dari buah markisa (Utami, 2015).

Untuk dapat mengoptimalkan pemanfaatan buah markisa, maka perlu produk olahan yang lebih bervariatif lagi (Puastuti \& Susana, 2014). oleh karena itu, kegiatan inovasi perlu dilakukan dengan menghasilkan olahan produk selain yang sudah ada (Anggorowati, Rahman, \& Wijayaningtyas, 2019). Pelaksanaan kegiatan inovasi olahan markisa kepada masyarakat sebagai upaya untuk membantu meningkatkan kualitas dan kuantitas produksi sirup markisa, serbuk markisa dan selai markisa diharapkan dapat menjadi produk unggulan dan meningkatkan pendapatan warga Kelurahan Sukorame Kecamatan Gresik. Pengabdian ini dilakukan oleh tim KKN 82 UPN "Veteran" Jawa Timur yang tergabung dalam KKN tahun 2021. Kegiatan ini terdiri dari 3(tiga) kegiatan pokok yaitu :

1. Menginventarisasi permasalahan dan produk olahan buah markisa, kemudian hasil dari kegiatan tersebut dibandingkan dengan literatur/referensi.

2. Mempelajari proses pada pembuatan minuman markisa. Menentukanvariasi olahan produk markisa. Mengumpulkan dan mencatat serta mempelajari data-data yang diperlukan. Membuat konsep desain kemasan yang menarik.

3. Mengadakan Gelar Produk, gelar produk sendiri adalah kegiatan sosialisasi, memberikan petunjuk pembuatan variasi olahan markisa, serta pemahaman bagaimana memasarkan olahan produk markisa dengan benar.

Menyadari adanya potensi permasalahan tim KKN 82 UPN "Veteran" Jawa Timur maka dipandang perlu untuk mengadakan kegiatan yang menunjang program ini yaitu untuk menangani berbagau permasalahan yang ada. Kegiatan tersebut antara lain memberikan Penyuluhan, Wawancara, Eksperimen untuk pembuatan variasi olahan buah markisa tersebut khusunya pada sirup markisa, serbuk markisa dan selai markisa.

\section{Cara Pembuatan Serbuk Markisa}

Tahapan pembuatan serbuk markisa yang memerlukan beberapa tahapan proses, sebagai berikut:

a) Mencuci bersih buah markisa

b) Memisahkan isi buah dari kulitnya

c) Menghaluskan isi buah markisa dengan blender dicampur dengan air dan menggunakan perbandingan 1:1

d) Memisahkan biji dari sari markisa dengan metoda penyaringan sehingga didapatkan sari markisa.

e) Setelah itu hasil sari markisa di tuang kompor yang sudah dinyalakan api kecil

f) Lalu diaduk terus hingga mendidih

g) Setelah mendidih dimatikan apinya tetapi dengan kondisi tetap diaduk terus hingga mengental dan muncul sedikit tekstur butler bulirnya 
Budi Prabowo ${ }^{1}$, Rafli Septian D ${ }^{2}$, Amalus Solecha ${ }^{3}$, Mustati'Uliyah ${ }^{4}$, M. Zidan Izani ${ }^{5}$, Lilis Nur Afiah ${ }^{6}$, Danang Suryo M. ${ }^{7}$, Maulana Taufik H. ${ }^{8}$, Rahma Amelia ${ }^{9}$

h) Setelah itu di jemur di bawah sinar matahari selama kurang lebih 2-3 hari dan tiap 20 menit sekali di aduk aduk dan dipisahin supaya tidak menyatu

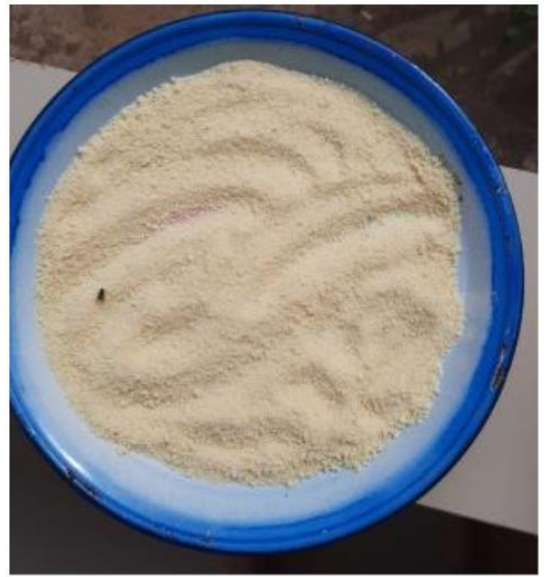

Gambar 1 - Proses Pengeringan

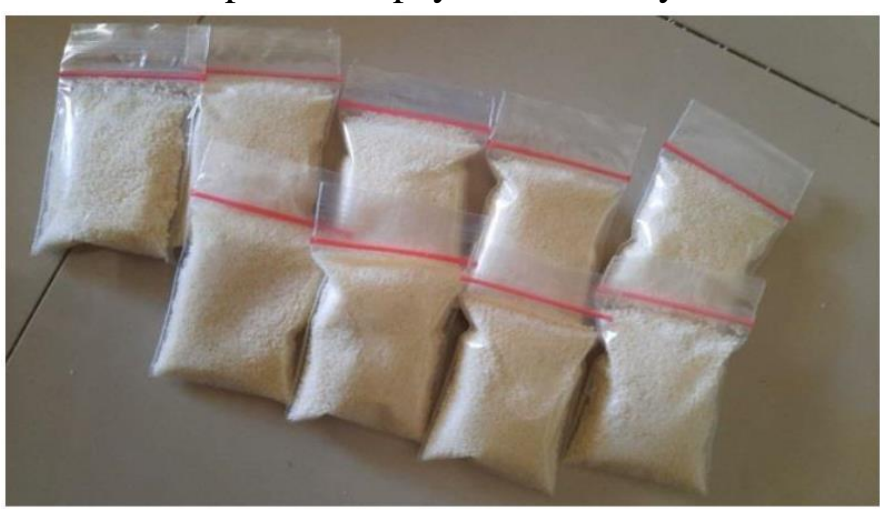

Gambar 2. Pengemasan Bubuk Markisa

\section{Cara Pembuatan Sirup Markisa}

Tahapan pembuatan sirup markisa yang memerlukan beberapa tahapan proses, sebagai berikut:

a) Mencuci bersih buah markisa

b) Memisahkan isi buah dari kulitnya

c) Menghaluskan isi buah markisa dengan blender dicampur dengan air dan menggunakan perbandingan 1:1

d) Memisahkan biji dari sari markisa dengan metoda penyaringan sehingga didapatkan sari markisa.

e) Setelah itu hasil sari markisa di tuang kompor yang sudah dinyalakan api kecil

f) Lalu diaduk terus hingga mendidih

g) Setelah mendidih dimatikan apinya tetapi dengan kondisi tetap diaduk terus hingga sedikit mengental

h) Sedikit mengental lalu api dinyalakan kembali dengan posisi tetap diaduk

i) Aduk terus hingga dirasa sudah kental dan pekat 


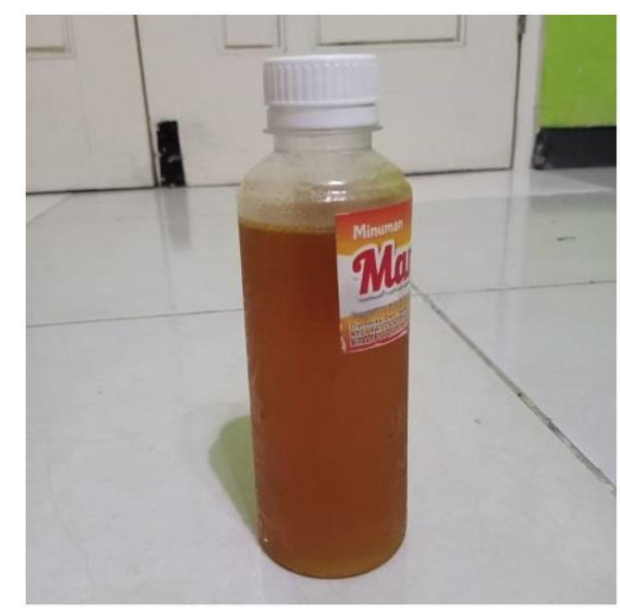

Gambar 3. Sirup Markisa

\section{Cara Pembuatan Selai markisa}

Tahapan pembuatan selai markisa yang memerlukan beberapa tahapan proses, sebagai berikut:

1. Mencuci bersih buah markisa

2. Memisahkan isi buah dari kulitnya

3. Menghaluskan isi buah markisa dengan blender dicampur dengan air dan menggunakan perbandingan 1:1, tambahkan gula sesuai selera karena buah markisa sendiri memiliki rasa asam yang cukup tinggi

4. Memisahkan biji dari sari markisa dengan metoda penyaringan sehingga didapatkan sari markisa.

5. Sari markisa dimasukkan kedalam wajan kemudian hidupkan kompor dan api sedang

6. Aduk terus menerus tanpa henti hingga sari mendidih dan berubah warna

7. Setelah sari buah markisa mulai berubah warna gunakan api kecil tetap aduk terus hingga memiliki kekentalan yang diinginkan jangan terlalu kental atau lama mengaduk karena dapat membuat sari markisa akan menggumpal

8. Untuk menandakan bahwa sudah menjadi selai adalah pengaduk mengambil sari markisa yang sedang dimasak dari bawah dan jatuhkan perlahan dari atas, jika sari yang jatuh tidak putus-putus maka matikan api kompor

9. Dinginkan sejenak sari markisa yang dimasak hingga suhu sari markisa \pm 30oC, kemudian siap dimasukkan dalam kemasan

10. Proses sealer dan pemasangan logo kemasan. 
Budi Prabowo ${ }^{1}$, Rafli Septian D ${ }^{2}$, Amalus Solecha ${ }^{3}$, Mustati'Uliyah ${ }^{4}$, M. Zidan Izani ${ }^{5}$, Lilis Nur Afiah ${ }^{6}$, Danang Suryo M. ${ }^{7}$, Maulana Taufik H. ${ }^{8}$, Rahma Amelia ${ }^{9}$

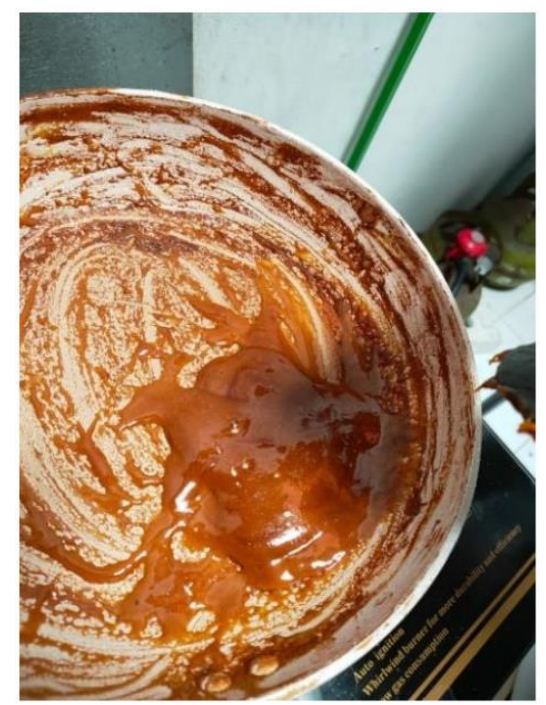

Gambar 4. Proses Pembuatan Selai Markisa

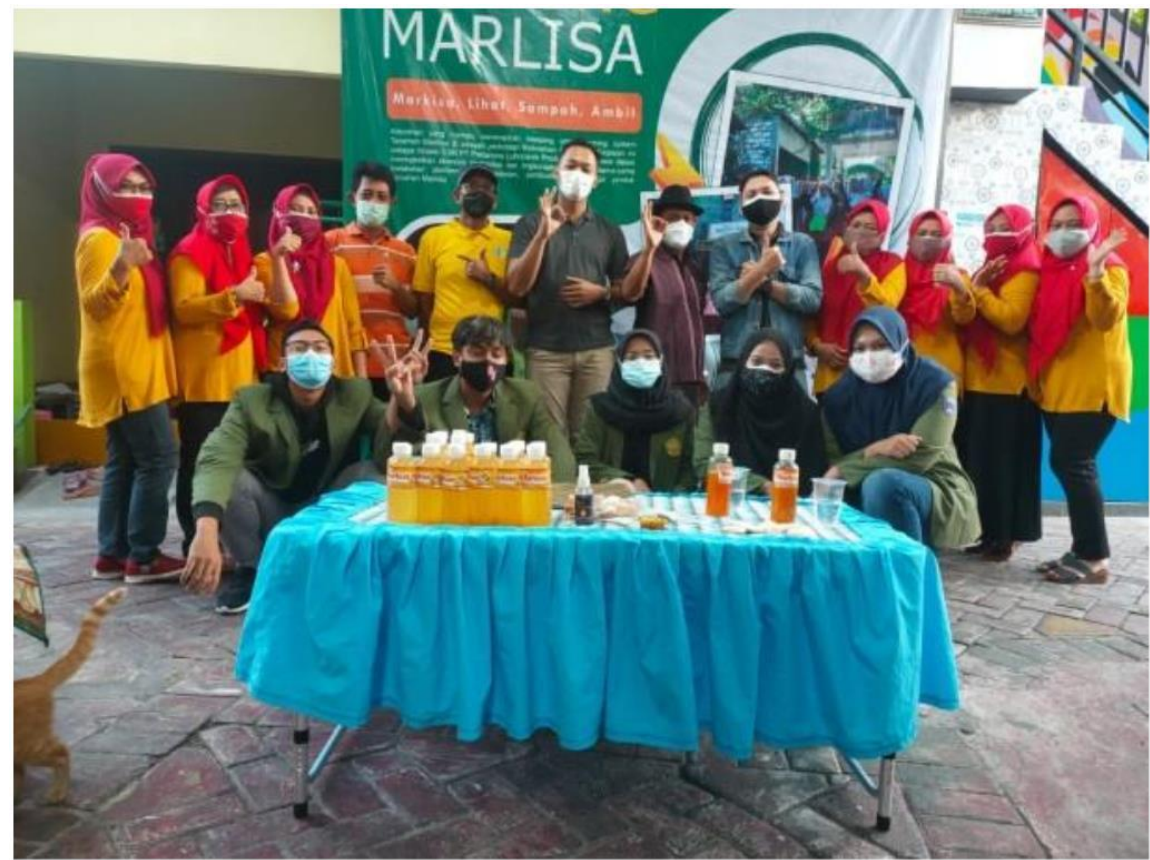

Gambar 5. Foto Bersama Warga Sukorame Ketika Gelar

\section{Kesimpulan}

Pemanfaatan buah markisa yang dilakukan oleh Kelurahan Sukorame adalah dengan menghasilkan produk olahan dari buah markisa, yaitu minuman dari buah markisa. Untuk dapat mengoptimalkan pemanfaatan buah markisa, maka perlu produk olahan yang lebih bervariatif lagi. Oleh karena itu, kegiatan inovasi perlu dilakukan dengan menghasilkan olahan produk selain yang sudah ada. Serta menjadi salah satu minuman khas yang hanya berada di kelurahan Sukorame.

Dengan melakukan pengolahan terhadap buah markisa menjadi produk olahan makanan / minuman yang siap jual, maka dapat meningkatkan nilai ekonomis dari buah 
markisa itu sendiri. Hal ini juga dapat berpotensi untuk dijadikan produk unggulan dari Kelurahan Sukorame yang diharapkan mampu memberikan pengaruh positif bagi perekonomian warga Sukorame.

Pelaksanaan kegiatan inovasi olahan markisa kepada masyarakat sebagai upaya untuk membantu meningkatkan kualitas dan kuantitas produksi sirup markisa, serbuk markisa dan selai markisa diharapkan dapat menjadi produk unggulan dan meningkatkan pendapatan warga Kelurahan Sukorame Kecamatan Gresik.

\section{Bibliografi}

Afifah, Rohmatun Nurul. (2015). Pengembangan Lembar Kerja Siswa (LKS) Ilmu Pengetahuan Alam Berbasis Metode Percobaan. Universitas PGRI Yogyakarta.

Anggorowati, Dwi Ana, Rahman, Nanik Astuti, \& Wijayaningtyas, Maranatha. (2019). Optimasi Proses Pembuatan Sirup Markisa Di Kampung Rampal Celaket Malang. Prosiding SEMSINA, 89-92.

Ihsan, Mohammad, Firza, Edy, Edward, Edward, Firmansyah, Firmansyah, \& Abdullah, Zulkifli. (2021). Ketahanan Pangan Nasional Melalui Diversifikasi Olahan Kentang Kayu Aro. Jurnal Karya Abdi Masyarakat, 5(1), 89-95.

Karsinah, Karsinah, Silalahi, F. H., \& Manshur, A. (2007). Eksplorasi dan Karakterisasi Plasma Nutfah Tanaman Markisa. Jurnal Hortikultura, 17(4), 83998.

Marpaung, Agustina Erlinda, \& Karo, Bina Br. (2016). Karakterisasi dan Evaluasi Markisa Asam Hibrid Hasil Persilangan Markisa Asam Ungu dan Merah (Passiflora sp.)(Characterization and Evaluation of Passion Fruit Acid Hybrid from Purple and Red Passion Fruit Acid Crossing). Jurnal Hortikultura, 26(2), 163-170. http://dx.doi.org/10.21082/jhort.v26n2.2016.p163-170

Puastuti, Wisri, \& Susana, I. W. R. (2014). Potensi dan pemanfaatan kulit buah kakao sebagai pakan alternatif ternak ruminansia. Wartazoa, 24(3), 151-159.

Qadaruddin, Qadaruddin, Nurkidam, A., \& Firman, Firman. (2016). Peran Dakwah Masjid dalam Peningkatan Kualitas Hidup Masyarakat. Ilmu Dakwah: Academic Journal for Homiletic Studies, 10(2), 222-239. https://doi.org/10.15575/idajhs.v10i2.1078

Sugiarti, Yuni. (2014). Perancangan sistem informasi agribisnis e-commerce buah 
Budi Prabowo ${ }^{1}$, Rafli Septian D ${ }^{2}$, Amalus Solecha ${ }^{3}$, Mustati'Uliyah ${ }^{4}$, M. Zidan Izani ${ }^{5}$, Lilis Nur Afiah ${ }^{6}$, Danang Suryo M. ${ }^{7}$, Maulana Taufik H. ${ }^{8}$, Rahma Amelia ${ }^{9}$

pisang. AGRIBUSINESS JOURNAL, $\quad 8(1), \quad 71-82$. https://doi.org/10.15408/aj.v8i1.5130.

Susanti, Yesi Ika, \& Putri, Widya Dwi Rukmi. (2014). Pembuatan Minuman Serbuk Markisa Merah (Passiflora Edulis F. Edulis Sims)(Kajian Konsentrasi Tween 80 Dan Suhu Pengeringan). Jurnal Pangan Dan Agroindustri, 2(3), 170-179.

Utami, Risty. (2015). Arahan Peningkatan Pelayanan Pasar Tradisional Agrobis Babat Kabupaten Lamongan-Referral Of Babat Agrobis Market Service Improvement In Lamongan Regency. Institut Teknologi Sepuluh Nopember.

Wirantasa, Umar. (2017). Pengaruh kedisiplinan siswa terhadap prestasi belajar Matematika. Formatif: Jurnal Ilmiah Pendidikan MIPA, 7(1). 